\title{
Digital Service Maturity: Development of an e-Cohesion-Specific Model ${ }^{1}$
}

\author{
Tamás LAPOSA ${ }^{2}$
}

This paper presents a new approach to measure the impacts of e-government concepts on the reduction of administrative burdens, in the domain of European fund management.

The present European legislation specifies that Member States shall provide online portal services for beneficiaries to reduce the administrative burdens of cohesion policy. This concept is marked with the term "e-Cohesion" in the scientific discourse. Based on former studies, the concept has several attributes that leverage its impact on burden reduction. Nevertheless, the level of their influence has not been underpinned by evidence-based research yet.

The present paper has three main aims. First, to present the methodology and findings of an international research on the capabilities and impacts of e-Cohesion portals. Second, to evaluate the relevance of the above attributes based on these findings. Third, to make suggestions for the development of an e-Cohesion specific maturity model to measure the effectiveness of electronic portals.

\section{Introduction}

Pursuant to Regulation 1303/2013 of the European Parliament and of the Council, Member States receive development funds from the Union through multi-annual programmes to support the implementation of the EU2020 strategy for smart, sustainable and inclusive growth, as well as the realisation of specific development objectives including social, territorial and economic cohesion. According to the regulation, the management and the delivery of funds shall be based on the principle of administrative burden reduction.

With regard to these provisions, the European Commission launched the e-Cohesion initiative to introduce the mandatory use of electronic portals and e-government solutions in the domain of fund management. [1]

In addition to the European legal provisions, national regulations can further extend the level of efficiency gains. As a result, e-Cohesion can be realised on differentiated stages of maturity as also proven by the study of the Commission and Deloitte. [2] This progress can be best addressed with the methodology of maturity models.

\footnotetext{
1 The work was created in commission of the National University of Public Service under the priority project PACSDOP-2.1.2-CCHOP-15-2016-00001 entitled “Public Service Development Establishing Good Governance” in the Concha Győző Doctoral Program.

2 Ph.D. student, National University of Public Service, Doctoral School of Public Administration Sciences; e-mail: tamas.laposa@gmail.com; ORCID: 0000-0002-4809-5796
} 
The European Commission and Deloitte made a specific e-Cohesion maturity model but it dominantly focuses on the functionality of e-Cohesion portals. Based on the analysis of e-Cohesion requirements and previous studies, four micro-level attributes (portal functionality, only once encoding, interoperability, one stop shop) and two macro-level attributes $^{3}$ (procedural complexity, extent of funds) were identified which may be relevant from the perspective of efficiency. Reviewing the pertinent maturity models, there is no specific model that can address the complexity of these attributes. Nonetheless, their relevance has not been confirmed by empirical research yet.

This paper presents and evaluates the results of an online survey conducted among e-Cohesion specialists and applicants ${ }^{4}$ of different Member States. The finding of the evaluation supports the selection of the relevant attributes for the creation of an e-Cohesion-specific maturity model.

\section{Conceptual Background}

\section{The Reduction of Administrative Burdens}

European legislation consists of a wide-ranging structure of different legal acts on all policy areas to guarantee the realisation of the underlying policy objectives. These rules are in direct effect in all Member States to ensure the seamless implementation of the strategic policy objectives. No doubt, the application of common rules has a strategic importance but the compliance with them has a series of costs on the other side. Citizens and legal entities are subject to different legal provisions which impose a wide range of financial, procedural or administrative obligations on them. All of these obligations incur different types of direct or indirect costs.

Consequently, a good regulation shall be effective and efficient. It needs to ensure the realisation of policy objectives at the optimal level of costs. Unnecessary legal provisions and regulatory costs represent a socio-economic loss. From a different perspective, the reduction of unnecessary obligations generates extra savings which can boost investment and innovation and contribute to economic growth. [3]

One of the above regulatory costs is labelled as administrative cost which is defined by the Standard Cost Model manual as "the costs incurred by enterprises, the voluntary sector, public authorities and citizens in meeting legal obligations to provide information on their action or production, either to public authorities or to private parties”. [4: 5]

Administrative costs can be spilt into two categories: cost of information obligations ${ }^{5}$ that would appear even in the absence of regulation (business-as-usual costs) and cost of information obligations which are directly connected to legal provisions (administrative burdens).

Micro-level attributes are linked to the technological context of e-Cohesion concepts while macro-level attributes describe the organisational and economical context.

4 Applicant means a public or private body or a natural person, responsible for initiating a funding project in the framework of a call for proposal.

5 Information obligations (IO) are the obligations arising from regulation to provide information and data to the public sector or third parties. [4] 
From a regulatory perspective, some administrative burdens are inevitable to safeguard the fulfilment of policy objectives and certain burdens could be eliminated without jeopardising the above strategic objectives. As a consequence, the reduction of administrative burdens is targeted at the latter category, the so-called unnecessary burdens.

As the first step of burden reduction, administrative costs and burdens need to be identified and quantified. The Standard Cost Model (SCM) provides a well-known methodology for the measurement of the administrative costs of regulations. The SCM is independent of the objectives of policy areas. It is applicable in different domains. The methodology provides coherent and comparable estimates and it is focussed on the administrative activities $^{6}$ and information obligations (provision of information, submission of data and documents) set by legislation.

The model enables decision-makers to break down regulatory requirements into elementary components to make the costs of activities measurable. In the SCM methodology, these components are labelled as cost parameters (Time, Price, Quantity, Frequency and Population) of administrative activities. Price measures the wage and overhead costs of administrative activities. Time represents the amount of time required for the completion of activities. Quantity indicates the size of the population of citizens and organisations affected and the annual frequency of the activity. These elements make up the SCM formula to calculate the costs of different administrative activities and administrative burdens of beneficiaries.? The formula is shown in Figure 1. [4]

Cost of an administrative activity $=$ Time $\times$ Quantity $\times$ Price Quantity $=($ Population $\times$ Frequency $)$

Figure 1. The SCM formula. [4]

\section{The Creation of the e-Cohesion Concept}

In 2007, the Action Programme for Reducing Administrative Burdens was introduced by the European Commission for the simplification of administrative requirements and the elimination of unnecessary administrative burdens of businesses. The above programme identified 13 priority key policy areas for the reduction of administrative burdens. Cohesion policy, as one of the selected priority areas, was estimated to bring about a $24 \%$ reduction of administrative costs. [3]

According to experts, the key factor of the above burden reduction is the provision of interactive portal services and the elimination of parallel paper-based business procedures. These online portal services can facilitate the interoperability of information systems

6 To provide the information for each data requirement, a number of specific administrative activities must be undertaken. The SCM estimates the costs of completing each activity. [4]

7 Beneficiary means a public or private body or a natural person, responsible for initiating and implementing a funding project selected for the reception of grants. 
and the re-use of already available data. The realisation of these measures can result in a significant efficiency gain by the reduction of burdens.

Following the above recommendations, the Commission launched an initiative to reduce the administrative burdens of cohesion policy and rural development policy by the utilisation of online portal service and e-government solutions. The initiative was labelled as "e-Cohesion” and its concept addressed a wide range of legal, procedural, organisational and Member State-specific factors. [5]

To ensure the expected level of efficiency, the Commission included the requirements of the e-Cohesion concept in the legal provisions of funding of the 2014-2020 period. Regulation (EU) No 1303/2013 of the European Parliament and of the Council nominates the three fundamental components of e-Cohesion: the provision of electronic data exchange services, interoperability of systems and the implementation of the only once encoding principle. These components have a direct impact on burden reduction.

The digital transformation of organisational procedures requires special guarantees to ensure the quality and efficiency of procedures, as well as the authenticity of digital transactions. These requirements are fulfilled by the establishment of collateral components such as e-document management, e-signature, and e-audit and interoperability. Their main requirements are regulated by the Commission Implementing Regulations (EU) No 821/2014 and No 1011/2014. [6] The structure of e-Cohesion components is depicted by

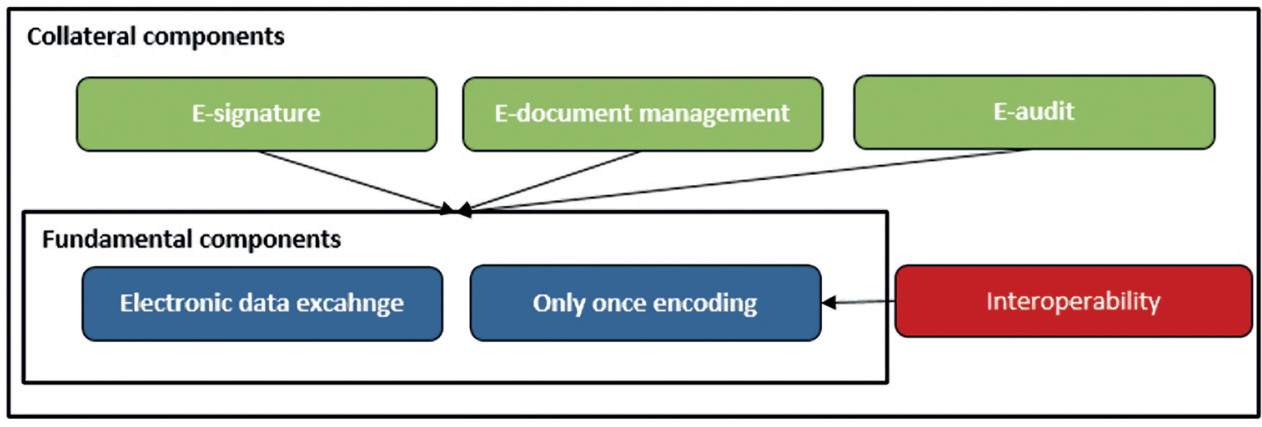

Figure 2. The e-Cohesion framework.

[Edited by the author.]

The Malmö Declaration and further Commission action plans on e-Government nominates the enhancement of the efficiency of government services, by the reduction of administrative burdens and the usage of information technology solutions, as a high level objective. [7] The prioritisation of the above approach also confirms the relevance of e-Cohesion.

\section{The Components of e-Cohesion}

Electronic data exchange: Member States shall ensure that all exchanges of information between beneficiaries with a grant agreement and relevant authorities can be carried out by means of electronic data exchange systems. 
Taking into consideration the specificities of national regulations, the European legislation leaves it to the Member States to make the use of e-Cohesion compulsory or optional to clients. It is also up to the Member States whether they provide electronic services for only beneficiaries or they make these services available to applicants applying for a grant, as well.

The expanding use of financial instruments-particularly when those are combined with grants-also brings a new area with some specific features where the interpretation of e-Cohesion is to be addressed. [8]

Taking into account the paperless nature of funding procedures, the regulations introduce special functional, operational and security requirements to guarantee the quality of services and the efficiency of procedures. [9]

The "only once encoding" principle and interoperability: In terms of the only once encoding principle, relevant authorities need to share all data and documents already submitted by the beneficiaries regarding the same funding project. This principle approaches the reduction of burdens from a procedural perspective. The application of this requirement excludes the possibility of multiple data requests and parallel information obligations. Its realisation is strongly connected to another e-Cohesion component-interoperability.

Interoperability can be defined as "the ability of disparate and diverse organisations to interact towards mutually beneficial and agreed common goals, involving the sharing of information and knowledge between the organisations, through the business processes they support, by means of the exchange of data between their respective ICT systems”. [9] [10] As a prerequisite of the only once encoding principle, the regulation sets the cooperation of authorities at the development programme level as a minimum requirement.

In the approach of e-Cohesion, interoperability has a special status. It is the collateral component of only once encoding but it also appears as a fundamental component. Fund management systems can interface with other national registries to retrieve and valid data on applicants and beneficiaries in order to reduce the number of data requested from them. This kind of interoperability is not mandatory by the concept of e-Cohesion but these solutions can reduce burdens directly and appear as a fundamental component.

E-signature: Considering the full-electronic nature of data exchanges, funding procedures require adequate authentication methods to ensure the veracity of digital transactions. The European legislation specifies that transactions carried out in the electronic data exchange system shall bear one of the three types of electronic signature defined by Regulation (EU) No 910/2014 of the European Parliament and of the Council. The applied method of authentication and the required level of security can be set by the national legislation in line with national requirements of verification and audit. [9] [11]

E-document management: The application of the e-Cohesion concept completely transforms funding procedures and the methods of document management. To cope with the challenges of this transformation, digital exchange systems need to meet specific functional, security and procedural requirements. From a functional perspective, information systems need to be equipped with a document management module to facilitate the day-to-day management of digital document flows. As regards security, systems need to comply with internationally accepted standards to ensure the veracity and integrity of documents. Procedurally, national authorities need to define the scope of accepted data carriers and the compliance criteria of digital documents. [12] 
Electronic audit: In certain cases, national audit and verification requirements and the paperless business procedures might be in conflict, so the concept of e-Cohesion needs to bring them in balance by providing guarantees for the compliance of documents and data while still enabling digital submission. For this reason, European regulations specify that the content of electronic exchange systems need to be regarded as reliable sources for audits and financial verification. This provision is ensured by the fact that electronic data exchange systems need to meet national legal requirements, compliance rules and security standards. [9]

\section{Main Attributes and the Maturity of e-Cohesion Concepts}

European legislations specify the main requirements of e-Cohesion to ensure a reasonable level of burden reduction. However, the compliance with these common requirements does not mean that the concept is utilised to its full potential. Regulations open the ground for Member States to further specify these requirements to adapt them to local economic, technological and societal conditions and to realise additional efficiency gains. This implies that national e-Cohesion concepts can be realised at different efficiency levels according to the approach and decisions of Member States.

Based on the research carried out by the European Commission and Deloitte, e-Cohesion can have a very impressive impact on the reduction of administrative burdens if it is implemented to its full extent. The study estimated that the concept can bring about an annual 8\% burden reduction if the highest level of portal sophistication would be implemented in all EU Member States. Taking into consideration these significant estimates and the potential socio-economic savings of burden reduction, e-Cohesion is worth studying more thoroughly.

To assist Member States in the full exploitation of the e-Cohesion concept, the Commission and Deloitte created a methodological tool, a maturity model, to measure the level of functional sophistication of national e-Cohesion portals and their potential impact on the reduction of administrative burdens. [2]

The first tool of maturity measurement (Capability Maturity Model) was introduced by the Carnegie Mellon University. [13] The review of the relevant literature shows that more than a hundred of models on different domains have been created since. [14]

Caralli et al. defines a maturity model as a set of characteristics, attributes, indicators or patterns representing progress in a particular domain or discipline. These models help organisations to evaluate and benchmark their practices, processes and methods against a clear set of standards or best practices of the given domain or discipline. Organisations can apply maturity models to define their current level of maturity and then determine the expected path of improvement. [15]

According to Bruin et al., maturity models are evaluative tools to assess and increase the maturity (competency, capability, level of sophistication) of a specific domain on the basis of an agreed set of criteria. [13]

A maturity model represents a desired evolution path for organisations or processes as discrete stages (a sequence of maturity levels). [14] The most frequently-used way of evaluation is a five-point Likert scale where Level 5 represents the highest level. Levels 
represent the transitional states in the model, they describe evolutionary steps or express a measurable attribute. Attributes are the core model components that appear on each level. They are based on best practices or standards expressed as characteristics, indicators or processes. [15]

In the model, organisations or processes advance between an initial stage and a final stage that represents total maturity. During this advancement, the capabilities of the organisations or their process performance progresses evolutionarily. The maturity model is a tool to determine the position of the organisation or the process on the evolution path by providing criteria and characteristics to be fulfilled to reach a particular maturity level. [14]

The e-Cohesion model of Deloitte is a useful tool to help positioning e-Cohesion portals and setting development targets but it applies a dominantly functionality-oriented approach. As supposed by previous papers, e-Cohesion is a more complex framework, so it is advisable to develop a maturity model that encompasses different micro-level functionality, only once encoding and interoperability, one stop shop and macro-level (procedural complexity, extent of funds) attributes. In this context, micro-level attributes contribute to the reduction of administrative burdens from a technological perspective while macro-level attributes define the organisational and economical context of e-Cohesion.

The impacts of these micro and macro attributes seem to be convincing although their relevance has not been underpinned by evidence-based research. For this reason, a previous paper described a research design for the impact-assessment of these presupposed attributes. [16] Based on this design, an online survey was conducted among experts of different Member States lately. The following sections summarise the findings of this survey.

\section{Methods}

The fundamental objective of the survey was two-fold: to discover the context of different national e-Cohesion concepts and to clarify the relevance of the presupposed e-Cohesion attributes.

Contextual questions try to map the scope of different e-Cohesion concepts (number of portals, number of back-office IT systems, types of funds managed, total funding budget managed by portals, type and number of development programmes managed).

The formulation of clarifying questions was driven by the supposition that attributes are cost drivers influencing the level of administrative costs in different ways. Following this logic, the nature of their influence can be described by different elements of the SCM formula. These questions link attributes with different SCM cost parameters (Time and Frequency) and measure the impact of the single attributes. The research focuses on only two cost parameters since they are the ones that can be influenced by the usage of digital services. The other two parameters (Population and Price) depend on external economic factors independently from the quality and efficiency of portal services.

The survey contains two groups of clarifying questions, perception-based ones and evidence-based ones. Perception-based questions focus on micro-level attributes and single portal functions while evidence-based questions focus on the procedural macro-attribute and the general performance of e-Cohesion portals. The impacts of the extent of funds attribute will be examined by secondary research in a different article. 
The perception-based question group measures the experience and expectations of respondents regarding different portal features on a 1-7 scale. It is important to note that all scaled questions use homogenous scales in the survey in order to make responses easily comparable. The structure and layout of perception-based questions is illustrated by Figure 3.

\begin{tabular}{|c|c|c|c|c|c|c|c|c|c|c|c|}
\hline 2.1 & Data retrieval from other databases & not available & (2) & (-) & 0 & (0) & O & (0) & ○ & $\begin{array}{l}\text { very frequently } \\
\text { used }\end{array}$ & $\begin{array}{l}\text { (2) have no } \\
\text { experience }\end{array}$ \\
\hline 2.2 & Automatic embedded controls & not available & (2) & (2) & 0 & 0 & 0 & 0 & (2) & $\begin{array}{l}\text { very frequently } \\
\text { used }\end{array}$ & $\begin{array}{l}\text { have no } \\
\text { experience }\end{array}$ \\
\hline 2.3 & Built-in guides & not available & (2) & 0 & 0 & (0) & O & (0) & () & $\begin{array}{l}\text { very frequently } \\
\text { used }\end{array}$ & $\begin{array}{l}\text { (1) have no } \\
\text { experience }\end{array}$ \\
\hline 2.4 & Automatic calculations & not available & () & O & 0 & () & 0 & 0 & ○ & $\begin{array}{l}\text { very frequently } \\
\text { used }\end{array}$ & $\begin{array}{l}\text { have no } \\
\text { experience }\end{array}$ \\
\hline 2.5 & Warning messages & not available & (2) & 0 & 0 & 0 & ○ & 0 & 0 & $\begin{array}{l}\text { very frequently } \\
\text { used }\end{array}$ & $\begin{array}{l}\text { have no } \\
\text { experience }\end{array}$ \\
\hline 2.6 & Interactive and pre-filled forms & not available & (-) & (-) & (-) & O & O & (0) & ○ & $\begin{array}{l}\text { very frequently } \\
\text { used }\end{array}$ & $\begin{array}{l}\text { have no } \\
\text { experience }\end{array}$ \\
\hline 2.7 & Online status tracking & not available & (-) & (-) & (2) & O & (0) & ○ & ○ & $\begin{array}{l}\text { very frequently } \\
\text { used }\end{array}$ & $\begin{array}{l}\text { (1) have no } \\
\text { experience }\end{array}$ \\
\hline 2.8 & Availability of different funds / calls via one portal & not available & (-) & 0 & 0 & 0 & 0 & 0 & (0) & $\begin{array}{l}\text { very frequently } \\
\text { used }\end{array}$ & $\begin{array}{l}\text { (1) have no } \\
\text { experience }\end{array}$ \\
\hline 2.9 & Direct access to main portal functions from main page & not available & () & (-) & (0) & (-) & ○ & ( & (-) & $\begin{array}{l}\text { very frequently } \\
\text { used }\end{array}$ & $\begin{array}{l}\text { (1) have no } \\
\text { experience }\end{array}$ \\
\hline 2.10 & Online chat with customer service & not available & () & (-) & 0 & 0 & (0) & (0) & 0 & $\begin{array}{l}\text { very frequently } \\
\text { used }\end{array}$ & $\begin{array}{l}\text { (1) have no } \\
\text { experience }\end{array}$ \\
\hline 2.11 & Data retrieval from previously submitted applications & not available & (0) & (0) & (2) & O & O & O & O & $\begin{array}{l}\text { very frequently } \\
\text { used }\end{array}$ & $\begin{array}{l}\text { have no } \\
\text { experience }\end{array}$ \\
\hline
\end{tabular}

Figure 3. Perception-based questions.

[Edited by the author.]

This question group examines eleven portal features classified according to micro-attributes. The features of portal functionality have been chosen following the requirements of Article 9 of the 1011/2014/EU regulation. [9] Previous studies analysed the hypothetical linkages between micro-attributes and cost parameters. The above features were selected according to these hypothesised linkages which are summarised by Table 1 .

Table 1. Hypothetical relations of micro-attributes and cost parameters.

[Edited by the author.]

\begin{tabular}{|l|l|l|}
\hline e-Cohesion attribute & Portal feature & Relationship \\
\hline Portal functionality & $\begin{array}{l}\text { Automatic embedded controls. } \\
\text { Built-in guides. } \\
\text { Automatic calculations. } \\
\text { Warning messages. } \\
\text { Interactive and pre-filled forms. } \\
\text { Online status tracking. } \\
\text { Direct access to main portal } \\
\text { functions from main page. } \\
\text { Online chat with customer service. }\end{array}$ & $\begin{array}{l}\text { Usability of portal functions facilitates } \\
\text { data processing (Time) and automatisation } \\
\text { and embedded controls reduce repetitive } \\
\text { information obligations and the chance of } \\
\text { corrections (Frequency). }\end{array}$ \\
\hline Only once encoding & $\begin{array}{l}\text { Data retrieval from previously } \\
\text { submitted applications. }\end{array}$ & $\begin{array}{l}\text { The re-use of already submitted data } \\
\text { and documents decreases parallel data } \\
\text { submission and accelerates the completion } \\
\text { of administrative activities (Time). } \\
\text { The utilization of validated data reduces } \\
\text { the chance of corrections (Frequency). }\end{array}$ \\
\hline
\end{tabular}




\begin{tabular}{|l|l|l|}
\hline e-Cohesion attribute & Portal feature & Relationship \\
\hline Interoperability & Data retrieval from other databases. & $\begin{array}{l}\text { The retrieval of valid data from other } \\
\text { databases substitutes data submission } \\
\text { (Time) and prevents corrective exchanges } \\
\text { (Frequency). }\end{array}$ \\
\hline One stop shop & $\begin{array}{l}\text { The usage of different accounts and } \\
\text { portals for the management of different } \\
\text { programmes makes the completion of } \\
\text { administrative activities more complicated } \\
\text { (Time). } \\
\text { The usage of different portals cannot } \\
\text { ensure the same level of error reduction } \\
\text { (Frequency). }\end{array}$ \\
\hline
\end{tabular}

Perception-based questions of the survey have three main sections which assess the same eleven portal functions from different points of view (Usage, Time, Frequency). The "Usage" section surveys the availability and popularity of different portal features in order to have a general view on their applicability. The "Time” section intends to explore the respondents' opinion on the impact of the single features on the duration of administrative activities. Finally, the "Frequency" section examines the impact of the features on the quality of data entry.

It is important to note that respondents were not familiar with the main focal points (attributes, cost parameters) of the research. These broader concepts might influence their judgements so they were asked to share their perceptions on more tangible concepts (portal features).

Evidence-based questions are aimed at the procedural attribute. In this section respondents gave answers according to a nominal scale. These questions intend to evaluate the procedural background of e-Cohesion concepts from the perspective of "Time" (number of data items and documents required) and "Frequency" (frequency of submissions during a project life cycle).

Two further evidence-based questions assess the general performance of portals (lead times and correction rates ${ }^{8}$ of different administrative activities) which may be influenced by both functional features and procedural factors. These estimates can support a further in depth research on the possible relations between the above two attributes.

During the selection of the target group, two main requirements were set. First, to reach respondents directly involved in e-Cohesion in order to receive real and valid answers. Second, to select respondents representing a wide variety of development programmes and e-Cohesion portals.

At first, the questionnaire was sent to certain experts known to have participated in the preparatory e-Cohesion discussions of the European Commission. Besides, the survey was also sent to representatives of the Managing Authorities and Joint Secretariats of various mainstream, interregional and transnational funding programmes. Thirdly, the respondents contacted were asked to forward the survey to other users, applicants or beneficiaries they can reach. According to preliminary expectations, the research was targeted to gather

8 Frequency of repeated administrative activities because of the incompleteness or incorrectness of already submitted information. 
at least 50-100 responses from different countries of the European Union so as to reach a statistically significant population.

It has been rather challenging to reach such a wide audience. The survey has been sent to almost four-hundred respondents all-over the Union and the online research took almost one month. At its closure, the survey received altogether 73 responses and its results are evaluated under the Results and Discussion section of the paper.

\section{Results and Discussion}

Concerning the population of the respondents, $68.5 \%$ of them represent a funding institution (Managing Authority, Intermediary Body, Joint Secretariat) and 31.5\% of them were applicants and beneficiaries. The answers were received from 21 Member States which almost covers the geographical area of the European Union. The division of countries (according to main geographical regions) is shown in Table 2.

Table 2. Countries of origin of the respondents.

[Edited by the author.]

\begin{tabular}{|l|l|c|c|}
\hline Geographical location & Responding countries & $\begin{array}{c}\text { Responses } \\
\text { (number) }\end{array}$ & $\begin{array}{c}\text { Responses } \\
\text { (\%) }\end{array}$ \\
\hline Central-Eastern Europe & $\begin{array}{l}\text { Austria, Croatia, Czech Republic, Hungary, } \\
\text { Poland, Slovakia, Slovenia }\end{array}$ & 32 & 43.8 \\
\hline $\begin{array}{l}\text { Norther Europe and } \\
\text { Baltic states }\end{array}$ & $\begin{array}{l}\text { Denmark, Estonia, Finland, Latvia, Lithuania, } \\
\text { Sweden }\end{array}$ & 19 & 26.0 \\
\hline Southern Europe & Greece, Italy, Portugal, Spain & 7 & 9.6 \\
\hline Western Europe & $\begin{array}{l}\text { Belgium, Germany, Netherlands, United } \\
\text { Kingdom }\end{array}$ & 15 & 20.5 \\
\hline
\end{tabular}

The study population covers a wide range of programme types. About two-third (64\%) of the institutional respondents represent mainstream (entirely Member State-specific) programmes and 36\% of them is dealing with interregional or transnational (more countries involved) programmes. The representation of European development funds covered by the survey is shown in Figure 4.

What kind of funds do you mange in you eCohesion portal? (multiple choice possible)

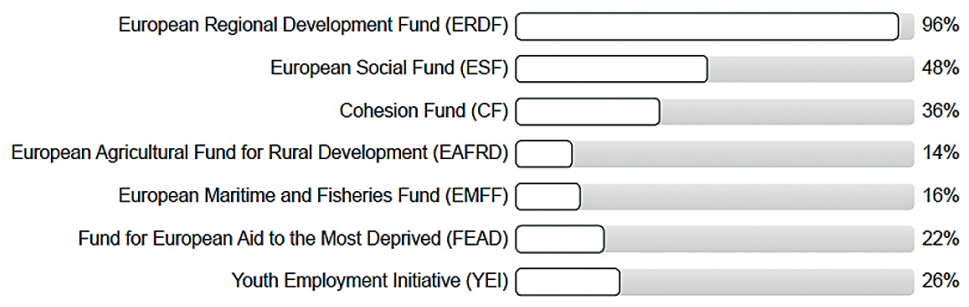

Figure 4. Representation of development funds.

[Edited by the author.] 
It is reasonable to suppose that the e-Cohesion concept has an impact on the number of systems and portals. The concept in itself does not restrict the development of programmespecific systems or portals. Meanwhile, the range of system requirements anchored in the current legislation increase development and operational costs, so the concept tends to shift Member States toward the concentration of IT resources.

As regards the information systems covered by the research, more than half (56.3\%) of the respondents said that a single e-Cohesion portal is used for the management of programmes. Another $39.6 \%$ indicated the use of maximum five funding portals and only $4.2 \%$ reported the usage of $6-20$ portals. These figures seem to confirm the above supposition but it is advisable to carry out a further in-depth analysis on the main drivers that influence the concentration of the number of portals.

The provision of electronic services is mandatory for all countries but their use can be optional or compulsory depending on the national legislation. Compulsory e-Cohesion can rationalise procedures and bring about a significant burden reduction. On the other hand, the optionality of paper-based and digital procedures may better address the preferences and needs of some target groups. At this point, Member States need to consider a wide range of factors such as penetration of digital technologies and e-Government solutions, the nature of procedures of the previous periods, digital literacy of applicant and equality of opportunities. $72 \%$ of those surveyed reported that e-Cohesion is compulsory in his/ her country of origin. The division of optionality between mainstream and international programmes is $50-50 \%$.

Member States need to make another crucial procedural decision to define their national e-Cohesion concepts. By the European legislation, digital services shall be provided for beneficiaries (applicants selected for funding and having a grant agreement) but may be extended to the application phase, as well. The complete digitisation of funding procedures can elevate the level of burden reduction and rationalise the management of projects. Meanwhile, the digital management of all applications may increase IT operational costs and capacity needs significantly. The survey shows that $90 \%$ of the responses reflect completely digital fund management.

The complete digitisation does not guarantee absolute burden reduction; it shall be introduced in an optimal way and tailored to programme-specific and country-specific factors. Nonetheless the above results reflect that countries and institutions approach e-Cohesion as a remarkable opportunity to completely digitise funding procedures and the reduction of burdens.

It is conceivably hypothesised that the procedural context has a dominant impact on administrative burdens by two main drivers: the number of data requirements ${ }^{9}$ (structured data and documents) and the number of legally prescribed information obligations. The number of data and documents requested can determine the duration (Time) of administrative activities fundamentally. The scope of information obligations can also leverage the frequency of activities. These information obligations cover mandatory (periodically repeated) information exchanges and optional (corrections) exchanges to

9 Each information obligation consists of one or more data requirements. A data requirement is each element of information that must be provided in complying with an IO. In the context of e-Cohesion, data requirements can refer to the electronic exchange of documents and data, including audio-visual media supports, scanned documents and electronic files. [9] [4] 
complement or correct previous information exchanges. Table 3-5 summarise the results of the survey regarding the above procedural factors.

Table 3. Division of responses_-data requirements (structured data) of different procedures.

[Edited by the author.]

\begin{tabular}{|c|c|c|c|}
\hline Number of data items & Application & Payments & Progress report \\
\hline $0-10$ & $19.6 \%$ & $19.6 \%$ & $28.9 \%$ \\
\hline $11-25$ & $10.9 \%$ & $39.1 \%$ & $35.6 \%$ \\
\hline $26-50$ & $23.9 \%$ & $17.4 \%$ & $28.9 \%$ \\
\hline $51-75$ & $6.5 \%$ & $8.7 \%$ & $2.2 \%$ \\
\hline $76-100$ & $13 \%$ & $8.7 \%$ & $2.2 \%$ \\
\hline $101-150$ & $17.4 \%$ & $4.3 \%$ & $2.2 \%$ \\
\hline more than 150 & $8.7 \%$ & $2.2 \%$ & $0 \%$ \\
\hline
\end{tabular}

Table 4. Division of responses_data requirements (documents and files) of different procedures. [Edited by the author.]

\begin{tabular}{|c|c|c|c|}
\hline $\begin{array}{c}\text { Number of data } \\
\text { documents }\end{array}$ & Application & Payments & Progress report \\
\hline 0 & $2.1 \%$ & $6.4 \%$ & $16.7 \%$ \\
\hline 1 & $6.3 \%$ & $6.4 \%$ & $2.1 \%$ \\
\hline $2-3$ & $12.5 \%$ & $10.6 \%$ & $31.3 \%$ \\
\hline $4-5$ & $14.6 \%$ & $17 \%$ & $20.8 \%$ \\
\hline $6-10$ & $29.2 \%$ & $17 \%$ & $10.4 \%$ \\
\hline $11-20$ & $27.1 \%$ & $14.9 \%$ & $4.2 \%$ \\
\hline more than 20 & $8.3 \%$ & $27.7 \%$ & $14.6 \%$ \\
\hline
\end{tabular}

Table 5. Frequency of information obligations of different procedures.

[Edited by the author.]

\begin{tabular}{|l|c|c|c|}
\hline Frequency of IOs & $\begin{array}{c}\text { Short-term projects } \\
\text { (0-1 years) }\end{array}$ & $\begin{array}{c}\text { Medium-term projects } \\
\text { (1-3 years) }\end{array}$ & $\begin{array}{c}\text { Long-term projects } \\
\text { (more than 3 years) }\end{array}$ \\
\hline 0-5 times & $73.9 \%$ & $24.4 \%$ & $10.6 \%$ \\
\hline 6 -10 times & $17.4 \%$ & $40 \%$ & $25.5 \%$ \\
\hline $11-15$ times & $8.7 \%$ & $24.4 \%$ & $27.7 \%$ \\
\hline 16-20 times & $0 \%$ & $6.7 \%$ & $10.6 \%$ \\
\hline 21-25 times & $0 \%$ & $2.2 \%$ & $8.5 \%$ \\
\hline 26-30 times & $0 \%$ & $0 \%$ & $4.3 \%$ \\
\hline more than 30 times & $0 \%$ & $2.2 \%$ & $12.8 \%$ \\
\hline
\end{tabular}

The results testify that the range of procedural requirements is rather differentiated. It is hypothesised that the number of data requirements and information obligations can directly influence administrative burdens. However, electronic portals can leverage and equilibrate these burdens by the reduction of corrective information exchanges by controlled data processing. Furthermore, portals can shorten the lead times of administrative activities by user-friendly interfaces, automatisation and the re-use of already available data. On 
the other hand, portals have no direct influence on the number of mandatory information obligations as they need to be completed according to legal requirements.

In order to verify the above assumptions, it is advisable to compare the level of data requirements with the efficiency indices (lead times and correction rates) of administrative activities of the analysed portals. The results are shown in Table 6-7 indicating different levels of lead times and correction rates, as well as the most frequent data requirements together with the proportion of their occurrence.

The comparison made refers to information exchanges related to application forms. This choice is based on the fact that the submission of application is the first information obligation in the project life cycle, so the vast majority of data and documents may be requested at this point.

Table 6. Comparison of lead times of application submission and data requirements.

[Edited by the author.]

\begin{tabular}{|l|c|c|}
\hline \multicolumn{1}{|c|}{ Lead time } & Number of data-items & Number of documents \\
\hline 0-30 minutes & 26-50 (25\%); 76-100 (25\%); $101-150(25 \%)$ & $2-3(25 \%) ; 4-5(37,5 \%) ;$ \\
\hline 0-60 minutes & $0-10(36 \%) ; 26-50(18,8 \%) ; 76-100(18,8 \%)$ & $6-10(45 \%)$ \\
\hline 60-120 minutes & $101-150(40 \%)$ & $11-20(50 \%)$ \\
\hline 2-3 hours & $0-10(42 \%) ; 26-50(28,5 \%)$ & $6-10(42,8 \%)$ \\
\hline 3-5 hours & $26-50(50 \%)$ & $6-10(50 \%)$ \\
\hline 5-7 hours & no responses & no responses \\
\hline more than 7 hours & more than $150(28,5 \%)$ & $11-20(62,5 \%)$ \\
\hline
\end{tabular}

Table 7. Comparison of correction rates of portals and data requirements.

[Edited by the author.]

\begin{tabular}{|c|c|c|}
\hline Correction rate & Number of data-items & Number of documents \\
\hline No correction & no responses & no responses \\
\hline Level 2 & $26-50(33.3 \%)$ & $4-5(25 \%) ; 6-10(25 \%) ; 11-20(25 \%)$ \\
\hline Level 3 & $0-10(33.3 \%) ; 26-50(33.3 \%)$ & $6-10(50 \%)$ \\
\hline Level 4 & $0-10(21,4 \%) ; 26-50(21.4 \%) ;$ & $6-10(21.4 \%) ; 11-20(21.4 \%) ;$ \\
& $101-150(21.4 \%)$ & more than 20 (21.4\%) \\
\hline Level 5 & $26-50(33.3 \%)$ & $6-10(33.3 \%) ; 11-20(33.3 \%)$ \\
\hline Level 6 & $76-100(50 \%)$ & $6-10(60 \%)$ \\
\hline Level 7 & $51-75(100 \%)$ & more than 20 (100\%) \\
\hline
\end{tabular}

Table 6-7 reveals no significant correlation between data requirements and lead times or correction rates, so the influence of the procedural context seems to be questionable. Based on these results the procedural attribute should not be incorporated in the maturity model but it is advisable to make a further in-depth analysis on their influence.

The above results may suggest that portal features influence the reduction of administrative burdens. Nevertheless, the relevance of the single portal features has not been confirmed. Table 8 shows the median values of the perception-based research on the relevance of portal features and e-Cohesion attributes. The results are shown in different columns according to the usage of features and their impact on the duration and frequency of administrative activities. 
Table 8. Results of the perception-based research on Time and Frequency.

[Edited by the author.]

\begin{tabular}{|l|c|c|c|}
\hline Portal feature & $\begin{array}{c}\text { Importance } \\
\text { (median) }\end{array}$ & $\begin{array}{c}\text { Time } \\
\text { (median) }\end{array}$ & $\begin{array}{c}\text { Frequency } \\
\text { (median) }\end{array}$ \\
\hline Data retrieval from other databases & 5 & 5 & 6 \\
\hline Automatic embedded controls & 6 & 6 & 6 \\
\hline Built-in guides & 5 & 4 & 5 \\
\hline Automatic calculations & 7 & 6 & 7 \\
\hline Warning messages & 6 & 6 & 6 \\
\hline Interactive and pre-filled forms & 6 & 6 & 6 \\
\hline Online status tracking & 6 & 5 & 4 \\
\hline Availability of different funds / calls via one portal & 6 & 5 & 4 \\
\hline Direct access to main portal functions from main page & 6 & 5 & 4 \\
\hline Online chat with customer service & 1 & 4 & 4 \\
\hline Data retrieval from previously submitted applications & 5 & 5 & 5 \\
\hline
\end{tabular}

Respondents were asked to score the relevance of portal functions on a 1-7 scale in the perception-based research. In order to evaluate the relevance of portal features, this paper sets the following requirements. First, relevant features shall be dominantly relevant among the vast majority of the respondents. Second, at least half of the respondents need to score relevant features in the upper tercile (scores above 4.66 i.e. at least 5) of the scale. Third, features need to be relevant at least from the perspective of Time or Frequency.

The first evaluation was based on the median values of the responses since it provides a reasonable approach to assess the results according to the above three criteria. This evaluation shows that all micro-level attributes may have relevance and three attributes (functionality, interoperability, only once encoding) met in the above requirements regarding both "Time" and "Frequency". The ones stop shop attribute met the requirements only in the "Time" column. Only the online chat feature had very low scores but it can be regarded as a special case since the majority of the study population reported to have no such function. Irrespective of this feature, the functionality attribute had very strong scores. Following this approach, almost all micro-level attributes worth further consideration to support the development of an e-Cohesion maturity model.

\section{Conclusion}

The e-Cohesion concept makes the utilisation of e-government services mandatory for Member States in the European fund management. Earlier studies of the European Commission have revealed that the provision of online portal services for beneficiaries can bring about a significant reduction of administrative burdens and improve the efficiency of fund management.

In addition to European legal provisions, national regulations can further extend the level of efficiency gains. As a result, e-Cohesion can be realised on differentiated stages of maturity as also proven by the study of the Commission and Deloitte. [2] This progress can be best addressed with the methodology of maturity models. 
The European Commission and Deloitte made a specific e-Cohesion maturity model but it dominantly focuses on the functionality attribute of e-Cohesion portals. Based on the analysis of e-Cohesion requirements and previous studies four micro-level attributes (portal functionality, only once encoding, interoperability, one stop shop) and two macrolevel attributes (procedural complexity, extent of funds) were identified which may be relevant from the perspective of efficiency. Reviewing the pertinent maturity models, there is no specific model that can address the complexity of these attributes.

However, the relevance of the above attributes has not been confirmed by evidence-based research yet. This paper analyses the relevance of the identified micro-level attributes and the impact of procedural complexity. The analysis is based on an online survey conducted among e-Cohesion specialists and users of electronic portals in EU countries. The survey received 73 responses from 21 Member States and covers different types of development programmes.

The survey intended to assess the general context of information systems and digital portals in EU fund management. Besides, participants were asked to give perceptionbased answers regarding portal features from the perspective of the main cost drivers of administrative burdens. Finally, respondents provided evidence-based data on the procedural context of e-Cohesion concepts and the usage of electronic portals.

The evaluation of the research indicates that all micro-level attributes are relevant from the point of view of burden reduction. Meanwhile, procedural context seems to be not as determinative as the impact of portal features. Nevertheless, it is advisable to conduct a further in-depth analysis on its impact. As stated above, the influence of the extent of funds managed by portals will be analysed in a different paper.

These results open the ground for a further and more extended research on the impacts and relevance of e-Cohesion attributes. Finally, the findings of the proposed research can be used to construct a more comprehensive e-Cohesion-specific maturity model.

\section{References}

[1] HAJDU Sz. - KONDOR Zs.- KONDRIK K. - MIKLÓS-MOLNÁR M. - NYIKOS Gy. SÓDAR G.: Kohéziós politika 2014-2020. Az EU belső fejlesztéspolitikája a jelen programozási időszakban. Budapest, Dialóg Campus, 2017.

[2] eGovernance study at EU/Member State level. Draft final report by Deloitte. Brussels, European Commission, 2012.

[3] Action Programme for Reducing Administrative Burdens in the EU. Brussels, European Commission, Office for Official Publications of the European Communities, 2007.

[4] International Standard Cost Model Manual_-Measuring and reducing administrative burdens for businesses. SCM Network, 2005. www.administrative-burdens.com (Downloaded: 10.04.2018)

[5] Draft opinion of the High Level Group. Administrative burden reduction; priority area Cohesion Policy, second opinion—eCohesion Policy. Brussels, European Commission, 2011. 
T. LAPOSA: Digital Service Maturity: Development of an e-Cohesion-Specific Model

[6] LAPOSA T.: e-Cohesion: How to intensify European fund management by electronic services. In. BALTHASAR, A. - GOLOB, B. - HANSEN, H. - KÖNIG K. MÜLLER-TÖRÖK R. - PROSSER, A.: Central and Eastern European e|Dem and e|Gov Days 2015. Budapest, 2015.

[7] NEMESLAKI A.: E-közszolgálatfejlesztés. Budapest, Nemzeti Közszolgálati Egyetem, 2014.

[8] BATÓ M.: National Regulatory Background for Financial Instruments established from the 2014-2020 ESI Funds-First Experiences in Hungary. European Structural and Investment Funds Journal (EStIF Journal), 4 (2016), 214-218.

[9] Commission implementing regulation (EU) No 1011/2014. Brussels, European Commission, 2014.

[10] European interoperability framework (EIF) for European public services. Brussels, European Commission, 2010.

[11] Regulation (EU) No 1303/2013. Brussels, European Parliament and Council, 2013.

[12] Commission Implementing Regulation (EU) No 821/2014. Brussels, European Commission, 2014.

[13] BRUIN, T. de - FREEZE, R. - KULKARNI, U. - ROSEMANN, M.: Understanding the Main Phases of Developing a Maturity Assessment Model. In. Proceedings of the $16^{\text {th }}$ Australasian Conference on Information Systems. Sydney, 2005.

[14] BECKER, J. - KNACKSTEDT, R. - PÖPPELBUSS, P.: Developing Maturity Models for IT Management-A Procedure Model and its Application. Business \& Information Systems Engineering, 13 (2009), 213-222. DOI: https://doi.org/10.1007/s12599-009-0044-5

[15] CARALLI, R. A. - KNIGHT, M. - MONTGOMERY, A.: Maturity Models 101: A Primer for Applying Maturity Models to Smart Grid Security, Resilience, and Interoperability. Pittsburgh, Carnegie Mellon University, Software Engineering Institute, 2012. DOI: https:// doi.org/10.21236/ada610461

[16] LAPOSA T.: eCohesion: How to measure the main drivers of administrative burden reduction. In. Central and Eastern European e|Dem and e|Gov Days. Budapest, 2018. 